\title{
EL ADVERSARIO Y EL COMPAÑERO. CUESTIONES ANIMALES $^{1}$
}

\section{THE ADVERSARY AND THE FELLOW. ANIMAL QUESTIONS}

\author{
Jonathan Pimentel Chacón \\ Universidad Nacional, Costa Rica \\ jonathan.pimentel.chacon@una.cr
}

Recibido: 29 de mayo / Admitido: 15 de junio / Publicado: 30 de junio de 2020

\section{Resumen}

El artículo presenta y discute dos recepciones contemporáneas de la idea de animal. En primer lugar, me ocupo de la concepción del animal como posible o efectivo adversario del ser humano. En seguida, trato con la idea según la cual los animales sintientes deben ser tratados, tanto afectiva como jurídicamente, como compañeros de los seres humanos. A partir de la consideración de las dos posiciones mencionadas planteo que, pese a sus diferencias, ambas están vinculadas por una metafísica de las capacidades personales desde la que se ofrece a los animales un nombre, una proveniencia y un fin.

Palabras clave: Animal, filosofía, naturaleza, persona, política

\section{Abstract}

This article presents and discusses two contemporary receptions of the idea of "animal". First, I deal with the conception of animal as an adversary to humans. Next, I discuss the idea according to which sentient animals must be treated, affectively and juridically, as fellows of human beings. Following the consideration of the later positions, I propose that, beyond their differences both are linked to metaphysics of personal capacities from which animals are offered a name, an origin and an end.

Keywords: Animal, Philosophy, Nature, Person, Politics

1 Este artículo forma parte de los resultados del proyecto de investigación 0435-14 (Evaluación del uso extenso del concepto persona), realizado desde la Escuela Ecuménica de Ciencias de la Religión, Universidad Nacional (Costa Rica). El antecedente inmediato de este escrito se encuentra en una cuestión que puede resumirse con la pregunta acerca de si es necesario personalizar a los animales para mantener con ellos relaciones que no partan del supuesto de que solo las personas pueden formar parte de un espacio de reciprocidad una de cuyas expresiones más significativas es el don de la bondad. 


\section{Introducción}

Discutiré dos recepciones contemporáneas de la idea de animal. La primera de ellas se concentra en la concepción del animal como adversario y la segunda en la idea del animal como compañero. En cada una de estas recepciones se describen formas de comprender y recibir los animales -algunos de ellos en todo caso - las cuales suponen e implican responsabilidades morales y compromisos metafísicos. Como parte de la discusión son tratadas de modo introductorio preguntas que se derivan de los planteamientos filosóficos: en especial las relativas a cuáles tipos de relaciones con los animales son deseables, posibles y justas. Me interesa de manera especial señalar algunos de los "desórdenes" que los animales causan en la metafísica, para usar la frase del pionero estudio de Fuller (1949)2 . La aproximación desplegada en este trabajo se concentra, en efecto, en la presentación de las representaciones filosóficas de los animales y destaca, dentro de ellas, algunos de sus presupuestos e implicaciones. La nuestra, entonces, es la cuestión, primero, de la exposición filósofica del animal o lo animal y, segundo, la de la representación filósofica ante el animal. En ambos casos, está claro, lo que está en juego es el destino de los animales puesto que, existe una relación - o muchas - entre la recepción del animal en la representación filosófica y las formas de estar ante él.

Mientras la filosofía representa a los animales - en la arena o en la casa - coloca ante sí los sueños que porta con respecto a los seres humanos y, también, presenta los retratos que hacen de sí cuando se presentan, detrás de la lengua, ante los animales. De modo que, la representación filosófica de los animales o lo animal, no está en el margen de la filosofía, sino que, por el contrario, sirve para expresar - cada vez que aparecen o desaparecen los animales - incluso un nombre o práctica fundamental de la filosofía: decir "animal", aglutinar dentro suyo múltiples vivientes y, gracias a la fuerza del nombre y al poderío técnico, entregar a "los hombres" o a las "creaturas

2 Dos son los "desórdenes metafísicos" que comentaré en adelante: la vida vulnerable del animal - la posibilidad de manipular su vida antes del nacimiento - hace que el imaginario enfrentamiento con lo sublime se debilite, lo cual hace que la representación filosófica (Wolff) cree, a partir de un sanguinario espectáculo, una metafísica del eterno adversario, desde el que surgen las características primordiales del "hombre". Luego, al ser el animal radicalmente otro, se hace necesario introducir una "modestia metafísica" que permita transformar - Kant mediante - a los animales en fines en sí mismos. La modestia metafísica propuesta por Korsgaard proviene, sin que ello sea paradójico, de un gesto metafísico magnánimo que consiste en integrar a los animales en una “esfera moral común” gracias a la atribución de características personales. 
humanas" la posibilidad de gobernar mediante su capacidad específica de apropiarse vida. Desde luego que, como se verá, no hay un sentido - en su sentido de dirección- unívoco para los animales en la lengua filosófica: en un caso hay animales (el toro adversario) que están inexorablemente destinados a la muerte y, en el otro, a una ecúmene creatural.

\section{I.El adversario}

Según el nominalismo del filósofo francés Francis Wolff "el animal no existe" (l'animal n'existe pas), por lo tanto, carece de eficacia promulgar "derechos animales" de forma genérica. En consecuencia, y como parte de su polémica contra el animalismo ${ }^{3}$, exige, por razones filosóficas y culturales, que se distinga de manera precisa entre tipos de animales para determinar, según casos, qué tipo de relaciones pueden ser establecidas - o prolongadas - entre los seres humanos y uno u otro animal. En todos los casos, cualquiera que sea el "contrato moral" establecido con animales, el deber inexpugnable de los seres humanos es, y debe ser siempre dice Wolff, preservar la vida humana. Desde un punto de vista normativo, lo que afirma el autor de Philosophie de la corrida (2007) es una jerarquía de los vivientes abierta al "cuidado" unilateral de los seres humanos hacia vidas inferiores. La noción inferior tiene dentro de la exposición del filósofo francés un significado preciso: una vida inferior es la que puede ser descartada sin que ello implique la ruptura del máximo artículo del pacto moral humano. De tal concepción se deriva una consecuencia también precisa: los animales humanos pueden decidir "casuísticamente" qué hacer con todos los animales inferiores. Es deseable, según Wolff, que se prolonguen las tradiciones humanas - de larga y arraigada existencia - en las que un animal es incluido en el mundo humano para ser matado.

3 Si se lee en comparación con un texto posterior - inequívoco desde su título: Manifeste animaliste (2017) - de Corine Pelluchon, se advierte de inmediato que la estrategia de defensa de la corrida de toros intenta, más que negar las demandas animalistas, consiste en asumir y depurar sus reclamos. Por eso, Wolff habla del respeto y la consideración que reciben los "toros bravos" antes, durante y después de su muerte en la arena. En el último apartado del capítulo I de su obra, el filósofo francés insiste y enfatiza sus diferencias con la "ética animalista", a la cual reprocha ser reduccionista: el propósito de la vida parece consistir en no sufrir. Para muchos animales y en particular para los seres humanos, afirma Wolff, sufrir forma parte de su especificidad como vivientes (hay sufrimiento, dice el filósofo, cuando se lucha por la libertad) y, por ello, no es deseable que el propósito de la ética consista restrictivamente en evitar el dolor. Wolff señala que contrario a una -la que él privilegia en su polémica- ética animalista: "la ética de la corrida" privilegia "la virtud activa" (Wolff 2007, Chapitre I: De la nature des taureaux et des devoirs qui s'en déduisent). La naturaleza del toro bravo se expresa en su capacidad de ser adversario y no, concluye el filósofo, en su pasividad sintiente. 
Ya que los animales son muchos, y cada uno de ellos es, desde el punto de vista de los humanos, distinto por su uso - del cual deriva Wolff una ontología particular para el "toro bravo" - es necesario responder cuál trato es deseable, posible y justo para animales particulares en contextos delimitados. Clarificada esta opción, el filósofo puede inscribir su intervención como un caso paradigmático de una filosofía de un animal. $\mathrm{O}$, para ser más preciso, de una filosofía de la creación de un animal cuya función es morir por mano humana. En efecto, la concepción del animal como adversario pretende ser parte de una filosofía cuyo objeto es la corrida de toros. Objeto extraño, pero no por ello ajeno a los problemas propios de la filosofía, dice Wolff. Atendamos a sus razones. En primer lugar, la corrida es considerada un objeto filosófico por su ambigüedad intrínseca, ya que ella reúne características de otros tópicos filosóficos (desde el arte hasta el deporte), sin ser reducible a ninguno de ellos. Junto con su ambigüedad Wolff coloca el tipo de "dilemas morales" que son también propios de la corrida como razones de su valor filosófico: "el hombre" arriesga su vida con el propósito final - y único - de dar muerte a la bestia4. $\mathrm{O}$, lo que es semejante, superar el terror que los animales pueden producir.

La corrida toda, todos los seres humanos que participan de ella anhelan la muerte. El anuncio mismo de la faena debe ser, por ello, una promesa de muerte. En el interior de tal promesa se encuentran una serie de mecanismos enfocados en el animal, el cual debe ser "nutrido por "el hombre" para enfrentarse a él en el momento adecuado. Contrario a la tradición teológica cristiana, o de lo relatado por Homero en La Odisea, la relación de los seres humanos con el "toro salvaje" no se encuentra incardinada en una teología; por el contrario, parece ser la puesta a prueba, en un espacio mínimo (la arena del redondel) en el que "el hombre" debe, si es que quiere preservar su vida, enfrentar la "irracional y fuerte" naturaleza. Tampoco es el hambre la que motiva la compleja armazón de una fiesta - o remanente de ritual o espectáculo - que lleva al borde de la extenuación a sus más inmediatos participantes. El éxtasis que produce la muerte del animal está precedido, debe estarlo, por pasajes en los que aquellos que ven cara a cara $^{5}$ lo salvaje acerquen a los otros

4 El capítulo 2 de Philosophie de la corrida (Pourquoi le taureau meurt) se dedica a explicar los motivos por los cuales en la "tauromaquia española" el toro debe morir. El motivo es uno y básico según Wolff: ella permite actualizar una lucha matricial en la que la "inteligencia heroica" derrota a la "fuerza bruta".

5 Aunque no se trata del levinasiano cara a cara (Levinas 2010 [1971], 78-80), Wolff insiste en que antes y dentro de la corrida el "toro salvaje" es tratado con el más profundo respeto con el que se puede tratar a un 
- al aficionado, al filósofo - tan solo un poco la posibilidad de ser heridos y herir de muerte. Dos planos complementarios componen la corrida, en el primero de ellos los humanos - organizados en una clara jerarquía - acosan a la bestia desde distintas posiciones, en el otro, "el toro salvaje" recibe solo ${ }^{6} \mathrm{el}$ acoso colectivo. Más que una definitiva lucha del hombre contra "lo salvaje", la corrida es una cuidadosa puesta en escena de una sustitución. En efecto, la corrida es un stage, no la tierra abierta en la que se encuentran solos "la bestia y el hombre”. El carácter filosófico de la corrida proviene de que ella es un artificio gracias al cual la muerte puede ser minuciosamente regulada y, al mismo tiempo, soberanamente gobernado "lo salvaje" que ha sido, con anterioridad, economizado. El anverso de la muerte de la bestia es el incremento de vitalidad que obtienen quienes participan efectiva y "espectacularmente" de ella: la filosofía, en este caso, es una reflexión amplia acerca de las emociones intensas en cualesquiera de las condiciones en que ellas surjan y se manifiesten. En el caso de la filosofía de la corrida, no se trata solo de reflexionar acerca de ellas sino de proveer criterios para su justificación.

\section{El juego de la muerte y lo sublime}

Según lo dicho, la corrida es una práctica total cuyo centro es un enfrentamiento entre "el hombre - los hombres - y un toro salvaje (taureau «sauvage»)" (Wolff 2007, Avant - Propos). Práctica total designa la conjunción de "collage" y aroma de sangre que condensa la corrida: sombras de muchas prácticas humanas aparecen en la arena -agilidad, fuerza, cálculo y estrategia- pero su luz particular es solo una, mutilar y matar la bestia. El estertor del "bravo animal", sin embargo, nunca satisface a los "hacedores" de corridas, ellos desean que se repita, quizá al acentuar sus rasgos más extremos, la lucha en la que, a través

\footnotetext{
"otro" que debe ser muerto. Dentro de la corrida, dice el filósofo, "el hombre se enfrenta a su otro" en un "cara a cara" desigual pero leal. Esto quiere decir que la asimetría en la que se encuentran es la única forma de encuentro en la que ambos pueden preservar su diferencia.

6 Cabe preguntar, y esto tiene relación con la nota anterior (5), si se sigue la argumentación de Wolff, si puede predicarse soledad para "el toro salvaje" o si, por el contrario, carece del tipo de facultades que son necesarias para experimentar tal estado. Según la división tripartita presentada en Philosophie de la corrida debe distinguirse entre humanos, cosas y animales, cada uno de los cuales es en sí mismo distinto de los otros y, tal distinción, exige un tratamiento diferenciado siempre visto desde el punto de vista humano. Debido a esa división es que el toro no puede aspirar a la soledad o la intimidad en el sentido que la explica el jurista italiano Stefano Rodotà, a saber, como vivencia intensa de la propia vida "al margen de todo control o interferencia" (Rodotà 2010, 135).
} 
de un solo hombre, ellos también se imponen a un temible animal. Arreglado todo lo necesario - en primer lugar, el animal - para que ocurra el "combate" cambia sincrónicamente el "modo de ser" de los participantes: ante todo, el distante filósofo ${ }^{7}$ que se incluye a sí mismo, cuando piensa la corrida, dentro de lo que podría ser una "heroica epopeya" o un ejercicio agónico de "dominio sobre lo imprevisible”. Mientras dura la corrida - cuya segmentación temporal está claramente establecida ab initio el espectador filosófico ve en ella desde una lucha hasta un arte, una secuencia continua cuya condición artística consiste en: "dar forma humana - familiar - a una materia bruta o al menos extraña: la envestida del toro" (Wolff 2007, Avant - Propos).

Es necesario añadir que además de dar "forma familiar" a los movimientos del toro - de integrarlos pues a una economía gestual típica - "el arte" del toreo da a los espectadores la oportunidad de participar una y todas las veces en la inscripción del animal dentro de un circuito en el que no puede ser más que un objeto, un lienzo donde "los hombres" trazan sus signos mortales. Si se considera como un arte, como lo hace Wolff, la corrida debe caracterizarse, en lo que aquí interesa, como un mimetismo sin reservas que intenta replicar, o hacer verdad, una arcaica imposición de un "hombre primigenio" sobre algo otro que animal, el monstruo. La corrida intenta copiar, en sus múltiples exhibiciones, una gesta; quiere ser guardiana de un evento fundamental que compone el devenir específico de lo humano: ponerse a prueba a sí mismo, dominar sus movimientos corporales, regular la excitación que producen los estímulos ambientales y, desde luego, reducir a una bestia. Según Wolff, la corrida, al ser recibida filosóficamente, muestra ser un archivo que nos permite acceder, actualizándolos, a aspectos básicos de nuestra ascendencia como especie. La filosofía de la corrida no es religiosa (no al menos en el sentido de lo religioso que brinda William James en la tercera conferencia de las diecinueve que componen su The Varieties of Religious Experience (James 1987 [1902], 55) ya que todo en ella es y debe ser visible además de corresponder con la inmanencia de los cuerpos.

7 Decía Guy Debord que: "la separación es el alfa y omega del espectáculo. La institucionalización de la división social del trabajo" (Debord 1992 [1967], 13 [25]) declaración que va muy bien con lo que ocurre con la filosofía que tiene como objeto la corrida. Pues tal filosofía está estricta y premeditadamente separada de aquello que tiene en mente, por lo cual es para ella un espectáculo que admite, como otras prácticas humanas, una división del trabajo: el torero arriesga el cuerpo, el toro es muerto y el filósofo organiza, como respuesta, un "monologue élogieux" que subraya su separación al mismo tiempo que convierte su intervención en el momento en el que el espectáculo se transparenta para sí mismo. Dicho de otro modo, el punto culminante de la corrida es su transformación en narración filosófica. 
El orden de la corrida es accesible para todos, la creencia de quienes de ella participan es que todo cuanto ocurre es la obra de sus manos, incluso "lo salvaje”. Dentro de la arena el gobierno de la vida depende de la astucia de la mirada y la precisión del movimiento ${ }^{8}$, la parsimonia devocional no tiene lugar allí, tampoco el frenesí.

Si lo sublime es aquello que produce terror o "la más intensa emoción de la que es capaz la mente" (Burke 2008 [1757], 36) el juego mortal contra el toro es terrible solamente en algunos de sus momentos. Al pensar la corrida el filósofo no está paralizado por el horror, tampoco está saturado por el "toro salvaje", la representación filosófica del "arte" de matar la bestia pretende alcanzar y comunicar los efectos inferiores de lo sublime: "admiración, reverencia y respeto” (Burke 2008 [1757], 53). Así es, para Wolff la filosofía de la corrida incluye admiración, pero no terror hacia la bestia, no porque ella no exprese un "feroz salvajismo" - en cualquier caso, este ha sido planificado - sino debido a que el terror "inmoviliza e impide pensar". Según el filósofo francés es precisamente lo opuesto lo que ocurre en el enfrentamiento escenificado en la corrida: frente al animal salvaje (lo sublime en la naturaleza) el "hombre" - o su epítome el torero, para ser más preciso - hace uso de sus capacidades distintivas para elevarse por encima del "objeto de terror". Para quien asiste al artificial "combate", el animal, del que se encuentra cómodamente lejano, es una excrecencia de lo sublime; todo iluminado y puesto para su observación en un campo de muerte, el "toro salvaje" es un poco más que celuloide. En el otro extremo puede que el "ritual" haga una promesa que deberá cumplirse por otros medios: matar la bestia, forma parte del proceso que concluirá con la derrota de la muerte.

Tener ante los ojos -- filosóficos - lo sublime y domeñarlo es una experiencia paradójica: el filósofo sabe que participa de una obra que no contiene lo terrorífico, sino que lo inventa retroactivamente. En el principio hay un combate, dice el filósofo, y, para que persistan "los hombres", el dicho enfrentamiento debe repetirse a perpetuidad. Para que ello ocurra, son necesarios el tiempo y el espacio para el combate, además de carne e instrumentos que

8 En una breve nota de Siegfried Kracaeur, cuyo título puede ser traducido como "Muchacho y toro. Un estudio en movimiento" (Kracauer 1995 [1963], 33-34), además de sintetizar el carácter espectacular y ornamental de una corrida, describe cómo el constante movimiento de la mirada, tanto de quienes están dentro de la arena como de los espectadores, está sostenido por la expectativa de la muerte del toro. Ello significa que el movimiento está supeditado a la idea fija de la extinción del animal. 
se enfrenten entre sí. Tanto el animal (el toro ibérico), como "los hombres" deben reiterar su "lucha" si es que quieren persistir. Laberinto de sangre que el filósofo desea eterno. El dolor, la angustia y el peligro de muerte producen regocijo y, como sugiere Burke, pueden impedir, cuando están asociadas al ejercicio y al trabajo, la "melancolía, la desesperación, y el suicidio" (Burke 2008 [1757], 122). El toreo puede entenderse como vida sublime, así parece hacerlo Wolff, puesto que une de modo especial el cuerpo y la razón y los incita a su máxima actividad.

Preciso es señalar de inmediato que el juego con la muerte, girar en torno suyo como si fuese algo que se tiene por los cuernos, es una exhibición de poder. Ella tiene la función de proteger, aunque ello sea por un corto tiempo, una íntima esperanza de la corrida, es decir que el toro sea, en efecto, el adversario. Ya que, si así fuese, se resolverían con su muerte las tensiones que anteceden y la atraviesan ${ }^{9}$ : ella es un hiato en el tiempo cotidiano; lo que ocurre al filósofo fuera de ese intervalo o lo que él imagina ocurrir pertenece a la arena, en ella muere o debe morir la bestia. Su muerte, sin embargo, no se extiende "fuera de sí misma", aunque excite escarceos líricos está cerrada definitivamente. De modo que, el filósofo y los espectadores tendrán que caer en cuenta de que incluso ante el fin del "toro salvaje" ellos deben enfrentar la (su) muerte. El animal no es un sustituto como lo fue el carnero en el caso de Abraham e Isaac (Génesis 22:13). Puede que la corrida suspenda momentáneamente la "tensión mortal" del espectador apasionado, pero también es cierto que una vez que termina el tiempo por el que ha pagado y debe desalojar "su lugar" su vida no puede ser sostenida por la muerte de la bestia ni por la faena del torero. Ni la una, ni la otra son transferibles o acumulables por el espectador. La mirada no alcanza para convertir lo acontecido en la corrida en el escenario de la propia existencia. La ostentación de poder condensada en el toreo es insuficiente para "acumular" y "distribuir" "modos distintos de ser" entre quienes son testigos de la actualización de un imaginado combate originario.

La corrida dice, según Wolff, que "los hombres" pertenecen a la misma familia porque han logrado imponer su destreza física y razón sobre la ferocidad salvaje de las bestias; tal dominio tiene una correspondencia teológica:

9 En cuanto espectáculo la corrida está antecedida y atravesada por desgarramientos personales y sociales, los cuales, según Wolff, son resueltos de raíz cada que el torero se enfrenta al "toro bravo". 
Yahvé, dice el libro de Los Salmos, domina el mar en el que hay "un hervidero innumerable de animales" y, además, a Leviatán al cual creó "para jugar con él” (Salmo 104, 24-26). El dios juega con los animales, en ello está sintetizada su especificidad como creador, los hombres de Wolff, los que participan de la corrida, incapacitados de crear como los dioses - pero sí capaces de modelar la tierra y sus creaturas - deben matar para elevarse sobre los animales. El juego mortal con "los toros salvajes" pertenece a un régimen de poder que concentra todas las energías disponibles en un único objeto al que debe destruir, mientras que el juego divino con "el mar y sus habitantes" permite la dispersión, el flujo ocioso de la fuerza. Diferencia de los juegos, distinto destino para los animales. En especial para el toro bravo.

\section{Animal bravo, hombre moral}

La ética de la corrida dice Wolff, debe aplicar el primer principio moral que nos une con los animales: "respetar el toro, pero no igual al hombre" (Wolff 2007, Chapitre I: Entre deux barbaries). Esto significa que constituiría una barbarie que en la corrida tanto el hombre como el toro tuviesen las mismas opciones de morir. Pese a ello, insiste el filósofo, es precisamente al tratarlo como un combatiente que se expresa respeto por el "toro bravo" ya que este se realiza en cuanto tal, en su enfrentamiento contra el torero. Por eso "defender al toro de combate", insiste Wolff requiere: "defender el combate de toros. En consecuencia, uno no puede al mismo tiempo defender el derecho a la existencia de la especie y el de los individuos, puesto que la sobrevivencia de la especie requiere admitir el derecho de matar a algunos de sus individuos" (Wolff 2007, Chapitre I: Différencier les espèces). Así planteado el problema con el que la ética de la corrida se enfrenta no puede ser resuelto al considerar a los individuos escindidos de su especie, en el entendido de que la sobrevivencia de la especie supone por necesidad la repetida muerte en combate de muchos de sus individuos. En otras palabras: que persista el sufrimiento de los toros de combate es una condición para que sigan existiendo. Esto es así porque desde el punto de vista de la moralidad del defensor de la corrida, el "toro bravo" es una cápsula sellada cuya vida no tiene más que un propósito: servir a un juego. 
La moralidad de la corrida se concentra en la especie y trata a sus individuos como ejemplares de una indiferente serie de rivales. Esto es así, admite Wolff, porque los animales que pertenecen a la categoría de los salvajes deben ser tratados en cuanto especie. Lo cual significa que, desde la perspectiva de las personas, los salvajes no poseen rasgos distintivos que los diferencien, tampoco ninguna característica que habilite o exija un trato afectivo particular. Con respecto a los salvajes, al toro, solo el enfrentamiento a muerte es admisible. La selección e integración de ciertos animales dentro de la categoría de los salvajes tiene como correlato la existencia de "animales domésticos", que son aquellos que, para las personas, poseen rasgos afectivos que los diferencian de todos los otros animales. Es decir, son aquellos a los que se transfiere o adjudica personalidad y, en consecuencia, son incluidos dentro del "círculo moral" de una o muchas personas. En relación con los salvajes, la recomendación de Wolff es tener una actitud "prudente" que sea capaz de determinar cuáles especies deben vivir y en qué condiciones deben hacerlo. Tal determinación debe seguir dos criterios básicos, primero el beneficio humano, luego el equilibrio ecológico.

La impersonalidad de los salvajes es, desde el punto de vista filosófico, una estrategia para cancelar en su raíz la posibilidad de incluirlos dentro del "círculo moral" de las personas. Las características de estos animales, ya sea que se planteen en términos de carencias o excesos con respecto a las personas, marcan el límite de sus vidas: serán siempre seres atrapados en su brutalidad y diferencia, sin mundo, pero sí por completo terrenales, e incapaces de construir por sí mismos su propio juego con los humanos. Así, el animal salvaje no está solo afuera de la casa, su distancia con respecto a las personas es mayor: no existen entre personas y salvajes similitudes suficientes que permitan establecer entre ellas una comunidad moral, sin que ello empeore sus existencias; salvajes y personas no pueden convivir; es decir, tener proyectos comunes, solo pueden combatir en la tierra. Su cohabitación puede tomar la forma de una "lucha leal” regulada por estrictas disposiciones o, simultáneamente, expresarse como exterminio. Con respecto al "toro de combate" Wolff afirma que por ser un "animal bravo" no es ni familiar, ni extraño, tampoco amigo o enemigo.

El "toro bravo" es un salvaje doméstico - integrado en el vasto margen de la casa para luego ser subsumido en el espectáculo - que antes y durante 
la corrida no puede ser familiar, como lo es "el gato de apartamento". De ello se sigue, dice Wolff, un secreto y una revelación:

Tal es la secreta ambigüedad de la personalidad del todo dentro de la corrida (a la vez peor amigo y mejor enemigo del hombre) que revela el doble sentido de la ética de la corrida (por un lado lucha trágica a muerte con el antagonista, y por el otro lado duelo lúdico de igual a igual con el compañero), y revela los dos sentidos entre los cuales titubea el concepto de bravura: entre la virtud sobrehumana del coraje y el instinto bestial de lo salvaje bruto. (Wolff 2007, Chapitre I: Des relations des hommes aux taureaux et des devoirs qui s'en déduisent)

El toro no es amigo o enemigo. Tampoco compañero o antagonista es, por el contrario, una bestia con instintos. Pero no se trata del instinto que enseña a los "pájaros el arte de la incubación" (Hume 2007 [1748], 95), sino de un comportamiento inducido, técnicamente logrado, que hace que el "toro bravo" ataque a "los hombres". Lo bravo del toro ibérico, además de ser, según Wolff, una característica "zootécnica" particular, forma parte de una relación contractual, a saber: el toro bravo existe, en buena medida, como "fruto de voluntad humana" y para ser parte de la corrida. Una vez establecido ese contrato - unilateral pues no podría ser de otra forma entre salvajes y personas - el "salvaje doméstico" debe ser considerado siempre un adversario, o, para usar el giro de Wolff, "su eterno adversario" (son éternel adversaire). A este, contrario a lo que podría pasar con un enemigo, ha de tratársele con respeto y dignidad, es decir ha de matársele rápida y francamente. Tal es el beneficio que obtiene el animal del contrato del que forma parte por voluntad de "los hombres". Las personas están dispuestas a poner en peligro su vida - aquellas que están dentro de la arena cara a cara con el toro - para matar a un "dios que combate". Para mostrar respeto por el "dios" en la corrida se garantiza, según el filósofo, que el toro entra en la arena "intacto en todos los sentidos del término". Esto quiere decir que precisamente porque su destino es la muerte, el toro debe afrontarlo "lleno de vida".

El momento de la corrida en el que el toro culmina su servicio como adversario de "los hombres" - como dios doblegable - es cuando recibe la última estocada. Antes, y de acuerdo con las "leyes taurinas", ha sido tratado con evidente admiración. La estocada final debe, dice Wolff, ser dada de frente, 
"cuerpo a cuerpo", "cara a cara”, para que "el hombre" ponga en efecto su vida en riesgo. Frente al toro, y sus mortales cuernos, el matador debe probar que es digno de dejar postrado al "eterno adversario". La prueba consiste en estar disponible para el animal, en ofrecer sus "huesos y sangre" y protegerlos sin suplementos. Solo pasada esa prueba es que es posible el "don de la muerte". Ya que el animal ha sido creado para ese último momento, la muerte es para él, según Wolff, un don que permite que complete el círculo de su vida. Un "toro bravo" que no muere en la arena, previos combate y estocada, no llega a ser completo "en sí mismo" y tampoco lo es "para los hombres”. Además, ya hemos visto que también algo en "el hombre" se trunca si es que llega a retirarse de la arena. El don al que se refiere el filósofo no puede ser recibido por su destinatario - nadie recibe su muerte, tampoco las personas - por eso la muerte del animal es lo contrario del don: es la rendición del otro. Ahora bien, según Wolff incluso en la sumisión se expresa el respeto al otro, a sus especificidades, a lo que lo hace radicalmente desemejante a "los hombres". Llevado por su admiración por la tauromaquia, el filósofo dice que si hay una práctica humana en la que es recibida la "personalidad" del toro ella es el combate que ocurre en la arena. Fuera de ella, en la pintura, la literatura y el mito, se exalta "al toro abstracto, símbolo de la bravura" (le Taureau abstrait, symbole de la bravura).

\section{Entre naturalezas}

¿De qué animal habla Wolff en su filosofía de la corrida? ¿Por qué puede ser el eterno adversario? Se trata, repite en muchas ocasiones, del "toro bravo": un animal dotado "como muchos otros salvajes de una suerte de instinto de defensa, que en su caso está muy desarrollado" (Wolff 2007, Chapitre I: De la nature des taureaux et des devoirs qui s'en déduisent). Además, tal instinto se ha desarrollado producto de la selección - intervención humana - a través de los siglos. Es la bravura del animal lo que produce la mortal admiración: el toro es difícil de manipular, resiste las aproximaciones humanas, intenta no estar a la mano de los humanos, no cede y esa es la raíz de la corrida. Antes de "enfrentar la arena", narra Wolff con tono enfático, el toro vive entre tres y cinco años "libre" en amplios campos, inmensamente más vastos de aquellos de los que "disponen todas las especies domésticas" y ahí vive de acuerdo con 
su naturaleza (insumiso, indomable, indócil, inadaptable), hasta que, acosado por "los hombres", enfrente la muerte con igual bravura.

El toro es portador de "una naturaleza desafiante" que el espectáculo taurino y su ética buscan manifestar; ya que toda tauromaquia tiene como base "la bravura, el furor latino, que se manifiesta en el ataque espontáneo, inmediato, violento, repetido", aún más toda la ética de la corrida consiste en permitir que el toro ataque, dentro de la arena, al hombre. Wolff transforma, con la anterior descripción, "el arte de la tauromaquia" en aquella práctica humana que permite al animal correr o perseguir a los seres humanos o, lo que es igual, expresar su naturaleza. Si el animal no fuese eso, un salvaje que quiere atacar, nada en la corrida tendría justificación - cabría pues aquella amonestación moral de Plutarco que imputaba que los seres humanos mataban solo a los animales más indefensos - y sería igual al exterminio. La filosofía de la corrida presupone una naturaleza e intenta sacar de ella toda su "bravura", es un procedimiento de exposición: pone frente a aficionados y toreros una extraordinaria narración en la que son ellos lo que, dentro del espectáculo, se defienden de la acometida de la bestia. Sin embargo, no es esa extraordinaria inversión de la corrida la más llamativa propuesta de la filosofía de Wolff, ella es que también los humanos pueden manifestar su naturaleza al combatir contra el toro bravo. El toreo es, según tal filosofía, un choque de naturalezas, y no un espectáculo o un "deporte sangriento", monumento móvil a la agilidad y decisión humanas de proveerse un adversario y matarlo en condiciones “asimétricas pero leales". Debido a que existe el adversario - eterno, porque la corrida se expresa históricamente, pero, cree Wolff, es condición de posibilidad de la historia - pueden "los hombres" actualizar y manifestar su naturaleza para cumplir con ello tanto un deber consigo mismos, como con los salvajes.

De modo que el adversario, además de estar naturalmente ordenado a ello, cumple su naturaleza cuando, provocado por "los hombres", los embiste hasta que es derrotado. El "toro bravo" es un animal excepcional que es respetado y adecuadamente recibido por las personas cuando es preparado para expresar su bravura en la arena. Pero, el animal es una plataforma, o mejor dicho carne y sangre, sobre la que se elevan "la ética heroica", "el héroe" y las virtudes que el filósofo imagina completan "al hombre" y lo hacen total. Cuánto más cualidades ambiguas y sublimes - en el sentido de Burke - atribuye el filósofo al "salvaje doméstico" más puede exaltar, y en efecto lo hace, el 
espectáculo de la corrida: arte en movimiento en el que se recupera un "pasado primordial”, se imagina y construye el futuro. La representación del adversario oscila por ello entre el dios y el héroe: "el toro bravo es para el hombre menos que un hombre, pero es casi un dios: es un héroe" (Wolff 2007, Chapitre I: De la nature des taureaux et des devoirs qui s'en déduisent).

La filosofía de la corrida no puede recibir al "animal", puesto que dice, tal "vida general" no existe. En su lugar transforma al "toro bravo" en "el adversario héroe" que no es animal, ni hombre, ni cosa, sino la aparición o encarnación de un mito. El toro ya no es un animal, debe dejar de serlo para satisfacer una inclinación filosófica: dotar a los hombres de un estatuto que los eleve por encima de la tierra, la sangre y los huesos animales. El filósofo traduce lo que sucede en la corrida en una escena totalizadora, en la que mediante un "hombre" todos "los hombres", gracias al derramamiento de un viviente excepcional, consiguen no ser mera naturaleza - puesta en la tierra para ser barrida por feroces bestias y la inescrutable muerte - sino un tipo nuevo de habitante de la tierra, uno que puede, al mismo tiempo, dar y quitar la vida de todo cuanto entra en su ámbito. No solo esto, ya que como explica Wolff, el "héroe adversario" proviene de voluntades personales. "El hombre" - mezcla de dios y héroe - crea eso que llamamos su "ámbito" para realizar dentro de ese indeterminado espacio sus juegos y espectáculos. Lo cual quiere decir que no está limitado a un "vasto campo" - como el "toro bravo" - sino que es el hacedor de un mundo que extiende para incorpar dentro de él animales y cosas. Incorporar remite en este contexto a ser el soberano que revela lo oculto o latente de la naturaleza, la hace expresarse y llegar hasta sus últimas posibilidades. El toro, devenido cúmulo de retazos míticos, es, una vez que ha pasado por la palabra del filósofo, no un objeto filósofico sino un elemento dentro de una zoofilosofía ${ }^{10}$.

10 Es preciso distinguir entre el uso que aquí se hace del término zoofilosofía, del empleo que hace de él, entre otros, el filósofo chileno Hernán Neira en un artículo reciente. La diferencia en el tratamiento de la noción radica en que para Neira zoofilosofía hace referencia a cualquier intervención filosófica que tenga como objeto a los animales (Neira 2017). En cambio, en el contexto de este estudio, tal noción hace referencia de modo exclusivo a una operación que permite a las opiniones filosóficas crear o prolongar relaciones unilaterales con los animales. Es decir, una zoofilosofía como la de Wolff habla sobre "el toro" con el propósito de defender lo que él imagina son "los hombres" cuando combaten con un adversario. En la zoofilosofía no se trata solo de que no interesa la pregunta por los "estados mentales animales" o su "capacidad normativa", sino que el "animal” está atrapado en la imagología de una máquina que de tanto exponerlo llega a desaparecerlo. El efecto de desaparición como resultado del exceso de exposición filosófica sucede también con la mostración espectacular de mercancías, que hace desaparecer el trabajo contenido en ellas. La particularidad de la zoofilosofía es su "atoramiento" conceptual: postula un estricto nominalismo en su punto de partida, para luego transformarse 
El perfil distintivo de la filosofía de la corrida, en cuanto ella es una reflexión acerca de pasiones intensas que surgen con el contacto con un animal, es formar al "eterno adversario", hacerlo nacer del cuerpo de un animal - sí, no de "los animales" - cuya muerte es posible y por ello deseable y justa. Posible porque "los hombres" se han esforzado en ello, deseable y justa puesto que de ella depende la estabilidad de una "la naturaleza", la de la bestia, y la extensión de otra, la humana. Si el animal no existe, como insiste Wolff en señalar, existen relaciones que se establecen con animales específicos los cuales son centrípetamente convertidos en "el adversario eterno". Quid pro quo.

\section{Compañero}

Puede concordarse con el criterio de Wolff acerca de la necesidad de no inscribir las relaciones entre los seres humanos y los animales, dentro de la categoría animal. No, al menos, sin señalar su composición interna y las consecuencias que de ella se derivan. Es decir, es necesario diferenciar, como sostiene el filósofo francés, entre animales, al reconocer contextos de relación e interpretar procesos históricos. Todo ello plantea hacer la filósofa estadounidense Christine M. Korsgaard cuando postula que "los seres humanos están obligados a tratar a todos los animales sintientes, es decir, a todos los que tienen experiencias subjetivas placenteras o dolorosas, como lo que Kant llamó "fines en sí mismo" al menos en un sentido de esa noción" (Korsgaard 2018, 11). La calificación contenida en la noción sintientes pretende delimitar de inmediato hacia cuáles animales es que Korsgaard considera que los seres humanos tienen obligaciones. Según esto, la sintiencia vincula en un sentido muy denso a seres humanos y animales, a tal punto que puede deshacer su usual oposicionalidad o jerarquización metafísica.

Para iniciar su explicación acerca de cuáles, qué son y por qué los humanos tienen obligaciones con los animales sintientes la filósofa elige una modificación en el vocabulario que estima usual. Por ello, su planteamiento general se inscribe dentro de una "filosofía de las creaturas" - en lugar de

en escritura ornamental de un espectáculo. La aproximación denominada “Anthrozoology” (Hosey y Melfi 2019) es alternativa a la zoofilosofía, ya que aquella procura entender las interacciones entre animales y seres humanos a partir de la comparación y síntesis de información surgida en "micro niveles" o diadas compuestas por animales (en especial domésticos o de granja) y humanos, para después postular algunos efectos benéficos de tales relaciones. La categoría zoofilosofía tiene relación, y de hecho creo que es completada, por lo que Rodríguez denomina "zoología filosófica occidental" (2015) en su importante estudio titulado Cantos cabríos. 
una filosofía del animal o una moral hacia los animales - en la que, a su modo, dice "el animal no existe". Existen en cambio creaturas o compañeros relacionados como se relacionan "niños de la misma familia". De modo que, el animal no existe. Tampoco los humanos. La categoría creatura, cuya familiaridad teológica reconoce de inmediato la filósofa, intenta superar la generalizada oposicionalidad que introducen las categorías humano y animal. La condición creatural se manifiesta en la "mundanidad" - terrenalidad sería más preciso - que caracteriza los "seres sintientes" que se encuentran "arrojados en el mundo" y realizan tareas vitales comunes: que van desde la reproducción hasta la convivencia con otras creaturas. Se sigue de lo anterior que las creaturas son un tipo de seres sintientes que hacen su vida en el mundo. Esa descripción, según la perspectiva de la autora, permite suspender la necesidad de especificar tipos de creaturas. Existen el mundo y las creaturas ${ }^{11}$. En aquel - que hemos de suponer es todo aquello que no son creaturas - los seres que deben preservar su vida tienen su única "habitación". En el mundo las creaturas tienen, además, una existencia que sienten y saben suya, diferente a la de las otras, ante las cuales se saben otros. En el mundo hay también lo no mundano y, cabe adelantar, no todas las creaturas son igualmente mundanas o, para decirlo con nuestro vocabulario, no todas tienen las mismas capacidades de hacer su mundo. Tal diferencia de capacidades se manifiesta en la forma como las "creaturas" se relacionan entre sí: las creaturas humanas son capaces de producir otras creaturas - en granjas industriales o laboratorios - para comerlas, experimentar y hacer productos con ellas. El arte humano hace posible, en efecto, una manipulación por entero asimétrica de otros seres sensibles. Así que, pese a que la introducción de la voz creatura podría tener como efecto una presentación menos disociativa de la relación entre animales, ella no consigue - y ese no es su propósito - eliminar la efectiva imposición de las creaturas humanas sobre las otras.

11 Es necesario precisar la formulación "el mundo y las creaturas", en sentido estricto existen un todo integrado por las creaturas, mundo, cosas que están interrelacionadas y se necesitan mutuamente para prolongar su vida y, más que eso, para que las creaturas consigan lo bueno para sí. El fundamento del todo que conforman es su propia relación en la que expresan diferencias. 


\section{Modestia metafísica}

De inmediato, y como consecuencia de aquella diferencia entre las creaturas, Korsgaard pasa de su minimalismo creatural, a una cuestión moral que concierne solo a las creaturas humanas: las obligaciones morales. La relación entre el "minimalismo metafísico" y "maximalismo moral" no contiene paradoja, aunque tampoco es ociosa. El minimalismo surge de una convicción de la filósofa: es necesaria la "modestia metafísica" para una convivencia "intercreatural”. Esta predica que los seres humanos, al ser descritos desde un punto de vista mundano, comparten rasgos fundamentales con otros seres. Tales rasgos no degradan a los seres humanos sino que los colocan en continuidad metafísica con un conjunto amplio de seres, al menos los sintientes. También, la modestia metafísica posee tesis robustas acerca de los atributos de las creaturas no humanas. La descripción de lo que Korsgaard llama "tareas para la vida" incluye agencia - en un sentido metafísico fuerte ${ }^{12} y$, en consecuencia, algún tipo de libertad. Las creaturas tienen una vida que formar y, para ello, deben ser capaces de evaluar su relación consigo mismas, otras creaturas y el mundo.

Según está perspectiva es posible combinar la modestia metafísica de las creaturas humanas con el robustecimiento metafísico de otras creaturas sin que ello implique una igualdad estática. A partir de la modestia metafísica es posible estatuir y desarrollar una perspectiva acerca de lo deseable acerca de las relaciones entre creaturas: sin negar las diferencias de sus atributos y capacidades por el hecho de pertenecer al mundo - o ser agentes mundanos sus relaciones deberían expresar su comunidad metafísica. Podría ser deseable que las creaturas cooperen entre sí, cada una de acuerdo a sus posibilidades, a las tareas para la vida que cada una debe cumplir para preservar su existencia. Con ello, se iniciaría la transición de una metafísica a una política, toda vez que la pregunta acerca de la posibilidad y las formas de cooperación pertenece al campo de las prácticas. Dicho de otra manera, lo que la filósofa estadounidense sugiere es que entre las consecuencias políticas de la modestia metafísica se encuentra la activación de la pregunta acerca de si es posible una política a partir de la comunión de las creaturas. Con lo cual, quedaría

12 Tal uso fuerte es planteado y desarrollado con amplitud por Helen Steward (2012, 70ss). Ella propone que, ciertos animales, poseen, si se consideran sus "movimientos" un tipo de libertad que es intrínseca de la predicada acerca de las personas. Según esta posición, el determinismo es incompatible con las actividades de una gran variedad de animales. 
suspendida la política soberana que decide unilateralmente qué hacer con la vida de los animales.

De inmediato se hace evidente que el engranaje metafísico y político descrito antes pertenece, tanto como el que intenta modificar, a una misma "familia metafísica" que puede tener efectos descriptivos y normativos distintos e incluso contradictorios. El elemento común de tal familia metafísica es que es dada en el lenguaje humano y sostenida por su fuerza: es una actividad que comunica una "tarea de la vida" de las creaturas humanas. La metafísica piensa retro y prospectivamente el conjunto de todas las tareas imaginables para ordenarlas de múltiples maneras. Las otras creaturas realizan "tareas vitales" sin embargo no poseen - o los seres humanos no contamos con los medios interpretativos adecuados para recibirla - una metafísica de tales tareas. Korsgaard mantiene que, pese a ello, tienen más importancia metafísica las "tareas" comunes que su ordenamiento en un discurso. Tal distinción entre práctica y exposición inteligible acerca de ella - no solo de su ocurrencia inmediata sino también de sus raíces, relaciones y sentido - asegura la idea de acuerdo con la cual los animales son agentes.

La modestia metafísica enfatiza que los vínculos deseables entre creaturas pueden ser establecidos (con suficiencia) a partir de la exhibición de sintiencia y agencia. Resta importancia por lo tanto a otros rasgos de las creaturas humanas - lenguaje, macro industria, posibilidad de aniquilar - a las que solicita plantearse a sí mismas la posibilidad de prescindir de la necesidad de adversarios. En cuanto a las otras creaturas, ellas parecen esperar que las creaturas humanas decidan qué será de ellas ${ }^{13}$. Y lo que sucederá, dice la filósofa, es que de la modestia metafísica surgirá (paso de lógos a légein sin derramamiento de sangre) una nueva economía mundial. Dicho de otra manera: una nueva administración de la comarca común en la que los seres humanos ceden su condición de amos. Tal condición está supuesta aquí como lo está la preeminencia del dios en la kenosis cristiana, en la que el creador oficia también de salvador después de "empequeñecerse" a sí mismo a la condición humana - se hizo doulos de sus creaturas dice el texto de la carta a los Filipenses- de la que no logra escapar con vida puesto que sus creaturas no logran reconocer en

13 La sección 1.1.3 está dedicada a extraer consecuencias acerca de "hechos cotidianos". Según Korsgaard todos los días "decidimos cómo trataremos a los animales" cuando "decidimos qué comer, qué vestir, qué medicamentos consumir o qué colocar en nuestro jardín”; es decir, el punto de partida en la relación entre las creaturas es asimétrico en el sentido que más puede interesar: el de la posibilidad de dar la muerte o preservar la vida. 
él a su creador y redentor. La suerte del dios devenido humano - por cierto poco interesado en otras creaturas que no sean las humanas - fue no menos sangrienta que la que tienen otros animales.

La filosofía reitera, con Korsgaard, el proceso de vaciamiento que hace posible una comunidad fundada en una asimetría que se bloquea así misma para hacer posible algo deseable y, dice la filósofa, bueno. Tanto la filósofa como el dios realizan una exhibición de poder que consiste en una benéfica restricción de su fuerza. Desde el punto de vista de la filosofía de las creaturas tal exhibición magnánima puede ser traducida políticamente como una cesión de poder cuya salvaguarda se encuentra en las manos - leyes, instituciones, sistemas de vigilancia y sanciones - de las creaturas humanas que se imponen a sí mismas, después de su kenosis, límites coherentes con el estatuto metafísico de las otras creaturas. Un círculo que intenta ser virtuoso sin proponer que el animal se haga humano, y tampoco que, el humano devenga animal. Podemos abandonar el vínculo teológico de la filosofía de las creaturas y concentrar nuestra atención en su similitud con el trato que ofrecen las personas - en un sentido lockeano - a los seres humanos que potencialmente desarrollarán comportamientos personales.

\section{Maximalismo moral}

Es necesario considerar el maximalismo moral de Korsgaard como un aspecto decisivo de su metafísica de las creaturas. El aspecto, según creo, que más contribuye a la idea del animal como compañero. Sin el maximalismo moral su metafísica creatural no derivaría en lo que, para la filósofa, constituye el núcleo de su propuesta: la transformación del trato hacia las otras creaturas, en tanto "fines en sí mismos" al menos en un sentido de tal noción. Una metafísica sin compromisos morales sincrónicos no sirve de nada. Tampoco se llega al "corazón de la filosofía" sino se plantean "preguntas mortales" (Korsgaard, 1.1.4 [21]). Tal denominación no es casual o hiperbólica puesto que de las respuestas que a ellas se ofrezcan se sigue la distribución de la vida y la muerte. Para las creaturas humanas la exigencia moral es exclusiva, solo ellas deben entender que sus acciones u omisiones son capaces de producir dolor y muerte. Acerca de las creaturas no humanas lo anterior implica que su agencia, libertad y mundo no está regido - no puede estarlo al parecer 
- por moralidad alguna. Sus "tareas vitales" no incluyen el tipo de libertad - y fuerza mundana - que hacen necesario plantear obligaciones morales o, más ampliamente, una moralidad. Transferir a las otras creaturas preceptos morales implicaría confundir entre paridad metafísica y simetría de facultades. La paridad metafísica no depende de la exhibición de facultades o, para ser más preciso, de que ellas sean fenomenológicamente equiparables a las de las personas humanas.

Entre los seres humanos la paridad metafísica de un infante y su madre no se sigue de la exhibición de capacidades sino de criterios minimalistas (la continuidad del aspecto convencionalmente humano, el reconocimiento de una comunidad) y, si ese infante crece hasta llegar a ser adulto y no logra desarrollar y demostrar capacidades personales, ello no implicará un cambio en su paridad metafísica. Hacia ese ser humano la comunidad inmediata y, sobre todo, el cuerpo político del que forma parte - una parte impersonal, está claro - tienen obligaciones morales maximalistas que deben, para ser efectivas, atravesar instituciones, leyes, códigos, reglamentos, espacios, regulaciones del tiempo y distribución de las posibilidades de gratificación. En este caso el maximalismo moral es una condensación y expresión óptima (buena, para usar el vocabulario de Korsgaard) de las características distintivas de las creaturas humanas. La anterior descripción no supone, al menos desde mi punto de vista, que no existan diferencias entre creaturas humanas no personales y creaturas no humanas. Tales diferencias son de diverso rango, pero ellas no requieren, para ser reconocidas, que las obligaciones sean distintas o, dicho de otro modo, es posible plantear que las creaturas no humanas deberían ser tratadas, al menos en parte, como las creaturas humanas no personales. Ahora bien, tal equidad supondría una distribución distinta de los recursos comunes que incluya una transformación de la metafísica, tanto como una economía que asuma como criterio de su funcionamiento "el dolor y el placer" de las creaturas no humanas.

El reclamo filosófico acerca de las obligaciones morales hacia otras creaturas presupone la paridad metafísica y la diferencia de capacidades. De esta se siguen responsabilidades cuyo objetivo es hacer posible limitar el dolor innecesario de las creaturas y, también, expandir su placer. El maximalismo moral de las obligaciones está de acuerdo con que las creaturas no humanas no poseen las capacidades suficientes para competir por el dominio del mundo 
- aún menos de defender su vida - con las creaturas humanas. Para disputar el mundo tendrían que desarrollar un arte semejante o más poderoso que aquel con el cual las creaturas humanas han conseguido elaborar, en parte para sobrevivir y, también para estar por encima de la tierra. A partir de esta diferencia en las técnicas de hacer mundo, se entiende que una obligación moral de las creaturas humanas consiste en admitir que, dada la paridad metafísica, los modos de hacer mundo de estas son importantes para comprender la realidad y las características del mundo, entendido como la totalidad interactiva de las múltiples maneras de hacer mundo, de transformar la tierra.

El mundo no es, pues, lo que hacen las creaturas humanas con la tierra, sino también la recepción y el cuidado que ofrecen a las otras formas de hacer mundo. Metafísicamente esto significa que el "mundo no es todo lo que hay en él”, es más bien las interacciones pasadas, presentes y futuras - la moralidad piensa en la deseable posibilidad del futuro - de los seres sintientes al interior de "un gran objeto físico". Ese mundo, en constante mutación, puede ser entendido como la cristalización de intercambios que forman espacios para habitar que se superponen y coexisten entre sí. Superposición y coexistencia no hacen referencia aquí a una "ecúmene creatural" en la que todas las creaturas se extienden, expresan y forman mundo; por el contrario, apuntan a tensas relaciones que, dice Korsgaard, suelen expresarse como irresponsabiliad y destrucción.

Visto desde el punto de vista de la filosofía de las creaturas, el maximalismo moral no aspira tan solo al cese de la rapiña. Su aspiración es, en efecto, que la moralidad sea entendida como una obligación hacia las tramas que constituyen el mundo. En virtud de una transformación de la concepción de lo que "hace mundo" es, que sería posible que las creaturas no humanas y también ellas sean en efecto fines en sí mismos. Al proseguir el programa de trabajo de la filósofa estadounidense cabe preguntar si la paridad metafísica incluye también la idea de que todas las creaturas son portadoras, por su común sintiencia, de las condiciones necesarias para compartir el mundo. Esto quiere decir que, si más que coexistir, las creaturas podrían vincularse para formar proyectos comunes como el que puede ser sintetizado en la cuestión de cuál debe ser la extensión de la vida de un animal (Korsgaard 2018, 1.2.3 [25]). Es claro que la condición de posibilidad de tal proyecto no es satisfecha con la declaración que afirma que los seres humanos y los animales "son iguales". 
En efecto, puesto que, en principio, tal declaración no considera la relación de los animales entre sí y con respecto a los humanos, a saber: en muchas situaciones los seres humanos decidirán, primero, cuáles animales son más importantes para ellos, también, tendrán que elegir a otros seres humanos en lugar de animales, ya que son más importantes para ellos. Esto no supone una variación en la paridad metafísica pero sí una diferencia derivada de lo que es más importante para los seres humanos y sus posibilidades de satisfacer sus preferencias.

Es en este contexto, en el que Korsgaard introduce el criterio cúspide de su maximalismo que en sus palabras dice: "es absolutamente bueno, bueno para todos, que cada creatura sintiente consiga las cosas que son buenas para ella, y evite las cosas que son malas para ella" (Korsgaard, 1.3.2 [32]). Tenemos un horizonte normativo, por entero plausible, si los seres humanos aceptan que "solo dentro de una anticuada visión teleológica del mundo" tiene sentido propugnar una mayor importancia para ellos en relación con los animales. Una interpretación de esta evaluación, centrada en los animales, es que ellos tienen mediamente claro, tanto como podría ser claro para una persona, qué es lo bueno para ellos. Si así fuese y de ser posible recibirlo - una alternativa para conseguir tal cosa podría ser la atención a la gestualidad del cuerpo en cuanto matriz y polo receptor de dolor y placer - entonces el mundo sería uno. Uno pero no por ello comunicado homogéneamente, con un solo lenguaje; pero sí referido a un único espacio en el que las creaturas buscan satisfacer sus necesidades. Tener medianamente claro lo que "es bueno" no es una característica uniforme entre las personas, incluso si el único criterio que poseen para determinarlo es el placer. Esto es así debido a que el placer puede, mediatamente, conducir a la enfermedad y la ruina o impedir las experiencias de "lo bueno". Al mismo tiempo, puede predicarse bondad de estados que, después de un tiempo, resultan insoportables en su totalidad; lo bueno, por ello, no ha de estar vinculado sólo al placer y tampoco a la convención moral, sino a uno o varios criterios que protejan siempre el bienestar de las creaturas.

Lo bueno, tal como es formulado por Korsgaard, no consiste en preservar la vida o en sobrevivir en condiciones precarias; por el contrario, instaura un horizonte más amplio y complejo. Por ahora, no tengo ningún criterio mejor que el de la "gestualidad corporal" para entender lo que los "animales quieren conseguir". La gestualidad corporal incluye una variedad de sintagmas 
somáticos que pueden ayudar a distinguir qué es bueno o no para los animales. Suponemos que las ideas acerca de lo bueno que crean los animales están asociadas a esos sintagmas y debemos responder a ellos. A partir de la relación con las creaturas no humanas, y la atenta recepción de su gestualidad, lo bueno podría contraerse, extenderse o revelarse de forma, considerablemente distinta, a la imaginada por las creaturas humanas. Sea de ello lo que fuere, la creatura animal es capaz de lo bueno, es decir de procurarse lo bueno y, puesto que hace mundo con otras creaturas, de dar lo bueno. Ya sea de forma directa o indirecta, cuando los animales consiguen lo bueno para ellos, ofrecen algo bueno a las creaturas humanas. De modo que, a su paridad metafísica se añade la reciprocidad de la bondad.

Tal reciprocidad, o los actos en los que ella se expresa, es la que convierte a las creaturas en compañeras. Si el mundo es bueno, es el resultado de las relaciones que establecen las creaturas entre sí; de la dación de bondad que se prodigan y que inscriben en sus lugares comunes. Los actos recíprocos que crean lo bueno hacen parte también de una concepción de lo justo que aspira a más que el dominio de la ley. En este caso, lo justo sería actuar de tal forma que se reconozca siempre que las creaturas animales valoran su vida tanto como las creaturas humanas y que, no hay justicia, en todos los casos, en los cuales son tratadas como si no fuese así (Korsgaard, 1.4.1 [36]). Toda creatura aprecia su vida - es lo más bueno para ella - y, agrego, aunque sea incapaz de manifestarlo constantemente debe entenderse que es así.

En vista de lo anterior, es necesario decir que cuando se dice que las creaturas aprecian o valoran su vida, hemos de entender, según una perspectiva animalista, que aprecian su cuerpo. Ahora bien, una vez que se asume que las creaturas son idénticas a su cuerpo sintiente - la sintiencia no requiere en este caso de la reflexión o de la representación - lo bueno no puede realizarse sin que afecte su estado corporal presente y futuro. Todo esto tiene consecuencias importantes en la presentación de Korsgaard, sobre todo si tiene en cuenta que, insiste ella, para los animales no existe una distinción entre tener y ser cuerpo. Es decir, el cuerpo es todo lo que poseen ${ }^{14}$. Puede

14 Podemos repetir aquí la pregunta de Anne Phillips: “¿Qué - si es que hay algo - hace el cuerpo especial?" (Phillips 2013,1) que la autora introduce como contexto de su indagación acerca del estatuto de los cuerpos humanos o partes de ellos en una economía de mercado. En el caso de los animales humanos lo especial del cuerpo es, y esto es casi evidente, que no existe el animal más allá de él y, por lo tanto, incluso suponiendo algún tipo de posible contrato que no incluya la coerción o la imposición, en el que el animal consienta la 
interpretarse que el cuerpo del animal pertenece a este de modo tal que podría usarlo para prolongar su existencia; si se somete a una relación en la que intercambie su fuerza por cuidado dentro de una casa, fábrica o ejército. Sin embargo, también cabe pensar que debido a que su cuerpo no es una entre otras de sus pertenencias - tampoco lo es para los seres humanos - sustraer su cuerpo del uso dirigido por la necesidad de cambio es actuar con justicia con los animales no humanos.

De ser así, corresponde a los animales (suum cuique) una posesión impersonal de sí mismos, dentro de una esfera moral en la que debe garantizarse, que el cuerpo es un fin. Desde el punto de vista de este planteamiento ningún fin es superior a la bondad que nutre los cuerpos. Los animales, en este caso, deberían recibir transferencias permanentes de los productos del trabajo humano que permitan, que mientras se extienden por la tierra no agoten el mundo de los animales o, mejor dicho, el único mundo. Para que las interacciones entre creaturas puedan crear un mundo justo es necesario que los seres humanos asuman el cuerpo del animal como límite intraspasable.

\section{Fines del animal}

Uno de los objetivos principales de Korsgaard es disputar la extendida creencia que afirma que los seres humanos son más importantes que los animales. Son distintos, sin duda, pero no hay ninguna razón relevante, dice la filósofa, para asumir su mayor importancia. Esas diferencias exigen de las personas - no de todos los seres humanos- obligaciones morales con las que, en coherencia con sus capacidades, contribuyen con la bondad del mundo. Es transversal a la ecúmene creatural una economía de la dación que no requiere la reciprocidad mediante el cambio, sino que encuentra su satisfacción o cumplimiento en lo bueno que resulta de una reciprocidad asimétrica. El tipo de organismos que son los animales tienden a ocuparse de "su adecuado funcionamiento" y también del de "sus crías"; es decir, cuidan de sí mismos y de otros en un sentido acotado. Los animales, en el sentido que Korsgaard usa el término en 2.1.7, además de cuidar, representan para sí la tierra en la que existen y tal representación instituye su mundo. Cuidar y representar

pérdida de todo o parte de su cuerpo - para crear un abrigo, por ejemplo - el daño a su cuerpo es el máximo daño que puede ejercerse a un animal. 
constituyen, en conjunto, lo que puede denominarse como síntesis de los fines de los animales.

Las acciones en las que los animales cuidan de sí expresan "el fin que portan dentro suyo": su bienestar. Los animales manifiestan con sintagmas somáticos diversos que para ellos lo bueno es no padecer hambre, sed, o miedo. Es precisamente por ello que puede ser afirmado que ellos se plantean qué es lo bueno. La vida de los animales - en efecto suya según esta descripción- es buena siempre que no es sometida a relaciones en las que se niega que tienden a lo bueno. Korsgaard considera que la asunción de la paridad metafísica - que en su explicación tiene múltiples puntos de inicio - con su consecuente adjudicación de agencia y fines para los animales, posee las características necesarias para despejar de ambigüedad en su comprensión de animal. Su explicación es efectiva desde el punto de vista de la delimitación: según ella no tenemos obligaciones morales con plantas o esponjas. No tener obligaciones implica no ser compañero, en sentido metafísico, de esos organismos. Ciertos organismos, una gran cantidad de ellos, no están orientados por fines. Tampoco lo están, además, una gran cantidad de seres humanos y animales. Ya sea porque pierden las facultades necesarias para ello o porque nunca las han desarrollado. En tales casos, debe ser asumido; sin embargo, que los fines están intactos si están presentes "la persona y el animal”. Estar presente no requiere la manifestación de agencia, ni gesto alguno, el cuerpo en el mundo. Con lo cual puede decirse que el símbolo de la creatura es su paridad corporal con otras de su tipo, de la que se deriva sincrónicamente la paridad metafísica.

Tanto cuando buscan su bienestar como cuando no lo hacen - o no pueden hacerlo - las creaturas están lanzadas al mismo tiempo al mundo y a un fin: su bienestar. Para que la posición de Korsgaard acerca de las creaturas se complete es necesario que ellas no requieran más atributo que su existencia para que sean receptores de obligaciones morales. Existir es, en su grado básico, una encarnación sin atributos. Mientras que en su grado máximo, supone una encarnación con extensiones en el mundo compartido; no solo una incorporación. El nacido existe, también el moribundo, igualmente quienes están incapacitados de comunicar su "vida interior" y quienes no pueden, en sentido amplio, "cuidar de sí mismos". De no considerarse que existe paridad metafísica entre aquellas creaturas que, siendo de la misma "familia", no tienen 
las mismas capacidades - al punto de que algunas entre ellas no logran nunca hacer de su "vida un proyecto"- entonces la propuesta de Korsgaard derivaría la paridad de la exhibición de capacidades. Según mi interpretación ese no es su propósito. Si atendemos a lo planteado en 2.2.2 es decisivo para entender el fin del animal no asociarlo con la funcionalidad - como si lo están los autos o los cuchillos - lo cual supondría que una vez cesada - por las causas que sean - se terminaría también aquello para lo que el este ha aparecido en el mundo. En lugar de función o funciones, las creaturas tienen o están orientados por un fin que no es exclusivamente su responsabilidad. Lo bueno, entendido como el fin general de todas las creaturas, se consigue si todas ellas, incluso sin desplegar funciones, viven buenas vidas.

Recibir a los otros animales como compañeros - un delfín, un cerdo, una jirafa - implica que ellos poseen algo análogo a lo que Korsgaard denomina "punto de vista" y, consecuentemente, un yo. A partir de ello, la comprensión del animal como compañero se concentra en la cuestión de si ellos poseen consciencia de sí. Asunto que la filósofa resuelve, después de algunos preámbulos, con su punto partida: ya que los animales sienten placer o dolor se sigue que tienen consciencia de sí. Esto es porque saben responder a los efectos que el mundo tiene en ellos. En todo caso, no se trata aquí de que el compañero es tal porque, abstraídas todas sus diferencias o tragadas por la "consciencia”, es no más que una réplica con cualidades inferiores de "uno mismo". Se trata, por el contrario, de hacer énfasis en la desemejanza radical que atraviesa las relaciones entre creaturas para, al mismo tiempo, garantizar su pertenencia a la ecúmene creatural. Admitir que los cuerpos que sienten están en paridad con el "sí mismo" personal, con todas las implicaciones que ello tiene - algunas especificadas por Korsgaard y otras no - es un gesto que salva, en todo caso, lo que podríamos denominar "la magnanimidad humana".

Bien visto, lo que propone la filósofa es, una vez más, un ofrecimiento en el que los seres humanos demostrarían todo lo que están dispuestos a dar o dejar - arcaicas teleologías y burdos egoísmos - para, como resultado de su desprendimiento, ampliar el "arco metafísico" que han creado para sí. La magnanimidad a la que hacemos referencia tiene un correlato bien entendible: el tipo de relaciones que los seres humanos han impuesto sobre los humanos parece no contribuir a lo bueno, ni siquiera para el bienestar de los animales humanos. Pero el compañero de Korsgaard, con todo y su 
paridad y las exigencias que introduce en el mundo de los humanos, siente solo aquello que le es dado sentir en la representación filosófica. Al ser tratados como compañeros, los animales no extienden su mundo, sino que son piadosamente integrados en el mundo humano para complementar o hacer posible la responsabilidad humana con las creaturas necesitadas, con la carne más abierta al influjo del mundo. Ellas comparecen, según Korsgaard, como sintientes cuya vida - bienestar - hace parte e incluso instituye la posibilidad de lo bueno. En todo lo anterior, la filosofía realiza cesiones constantes que olvidan que compañero - que es mi traducción de la palabra inglesa fellow la cual referencia a alguien que contribuye con dinero con otro para una empresa común - es, en su sentido más fuerte, aquel con quien compartimos el pan, es decir con quien nos nutrimos de una misma fuente, en este caso la tierra. Además de sintientes o potencialmente sintientes -cuerpos humanos o animales insensibles no dejan de ser humanos o animales según lo que plantea Korsgaard - las creaturas son quienes se alimentan en y desde la tierra.

Por alimentarse de la tierra, por ser ella indespensable para ambos al punto de que el mito predica de ambos ser "tierra", es que son compañeros. Necesitan, cada uno de modos distintos, hundirse en la tierra para prolongar su vida. Tal relación con la tierra es condición de posibilidad del hacer mundo - al salir de la tierra primigenia los humanos levantaron sobre ella, como si con ello pudiera ocultar su llamado, edificaciones que luego han devenido ciudades y conjuntos superpuestos de ellas - solo que los seres humanos han imaginado que la expresión de sus máximas capacidades consiste en, una vez llegados al fondo nutricio, salir y erguirse sobre él para controlar el circuito de su vida. ¿Puede volver a ser compañero el edificador de ciudades? ¿No implicaría ello "caer" en la indiferencia? No me refiero aquí a si es posible que una u otra reciban a los animales como compañero, sino a si es posible que los "sentimientos morales" de quienes se han levantado, en efecto, no solo sobre sino contra la tierra, compartan el pan con los animales. La filosofía de las creaturas de Korsgaard tiene olor a tierra nutricia, pero en su caso parece que falta trabazón entre el tiempo histórico y el tiempo de su filosofía. Tal parece que olvida que ya no habitamos la tierra; es decir que ha sido sometida a tal punto que para iniciar una nueva relación con los animales sería necesario una moratoria del modo de hacer mundo que parece regular el tiempo de la tierra. La filosofía de las creaturas parece implausible no por razones metafísicas 
sino políticas ${ }^{15}$. Para tratar a los animales como creaturas, y que ello se haga en todas las circunstancias, sería necesario más que la elaboración de máximas morales una transformación en las capacidades humanas de recibir al animal más allá del poder sobre él, el uso, la actividad y la pasividad. Lo cual supone una forma de barrido de la fuerza humana que debería esperar a que surja algo completamente nuevo de aquello que ha tenido a su lado: el animal.

\section{Cierre}

En la tradición filosófica hay quienes (Plutarco) han defendido que el maltrato a los animales tornaba bestias a los seres humanos. La suposición de tal postura es que cuando los humanos desplegaran sus características más específicas recibirían a los animales como lo hacían algunos dioses: como objetos de contemplación y fuentes de gozo. Pero, los seres humanos no son dioses, sino que, se encuentran con los animales cuerpo a cuerpo. Todos ellos, animales y humanos, son distintos entre sí. De haber algún un dios entre ellos sería, sorpresivamente, algún animal. Ante este los seres humanos, para encontrarse consigo mismos, para manifestar su naturaleza, deben prolongar un juego cíclico de muerte. No todos los animales son adversarios, dice el filósofo francés, sin embargo, sí lo es el "toro bravo".

Según lo instituido por Wolff, el toro está dispuesto metafísica y técnicamente para cumplir en el mundo solo una función, a saber, ser sacrificado en la arena. Es posible, deseable y justo que un animal "creado" para luchar y solo para ello, muera como adversario. Imaginar, o transformar el "toro bravo" en "eterno adversario", permite conseguir dos propósitos de la filosofía de la corrida. Hace posible representar un espectáculo primero como un arte collage y luego como "filosofía hecha con el cuerpo", la razón humana desplegándose a sí misma, mientras el torero esquivo, engaña y mata a un “dios”.

15 La filosofía de Korsgaard no hace parte de la zoofilosofía. No obstante, sus procedimientos "descriptivos" oscilan entre la cesión de la "fuerza de la persona" y la personalización de los animales, lo cual forma un bucle en el que se neutralizan los animales. Esto es así puesto que, para lograr la paridad con los seres humanos, los animales deben quedar ya no a la mano, pero sí sostenidos solo en la lengua y protegidos por el vaciamiento - al menos metafísico - de los animales humanos. Entonces, lo que resulta clave de la filosofía de las creaturas no es la comunicación de una experiencia de lo animal sino de un camino en el que la filosofía renuncia a una imagen del ser humano - al hacerlo descubre la fuerza de su capacidad de nominación - o, mejor dicho, la somete a una confrontación de la que no podría salir como era antes: es una creatura de la tierra. Todo el periplo confirma que el animal no es un compañero sino aquel viviente que recibe nombres y destinos asociados a ese nombre. 
Luego, hunde en el fondo ignoto de un tiempo primordial una práctica - la corrida - que no es objeto de indagación sino fundamento de sí misma, plataforma antropológica cuya operación más básica consiste en garantizar que "los hombres" puedan disponer de los animales como aquel tipo de viviente que, pese a su cercanía posible o efectiva, es metafísicamente foráneo. Wolff afirma que cada animal particular tiene una naturaleza que, para ser satisfecha debe alcanzar su fin y que, además, los "hombres" se realizan a sí mismos - aunque puede ser obvio es necesario decir que la filosofía de la corrida es un saludo nostálgico a una virilidad que parece extinguirse entre lentejuelas - cuando llevan a término el fin del animal.

Una filosofía de las creaturas como la de Korsgaard debe insistir, en coherencia con sus propios presupuestos, en la idea según la cual para que exista el mundo y este sea bueno, humanos y animales deben participar de una asimétrica - y por ello justa - economía bondadosa. En ella, los seres humanos pueden vivir vidas buenas solo si, como parte de sus "tareas vitales", donan a las otras creaturas - que desde el principio están exentas del intercambio, el alquiler o venta de su cuerpo a cambio de lo necesario para sobrevivir - tiempo y espacio para hacer su mundo. Ya que, en el hacer mundo de los animales, se encuentra una intrínseca bondad que, aunque no sea transferible a los humanos y, mucho menos, tenga una función o utilidad para ellos es imprescindible para que el mundo sea bueno. El corazón - animal, desde luego - de la filosofía de las creaturas consiste en aceptar la disparidad de las capacidades entre personas y animales - análoga con la disparidad entre humanos y personas - e incluirla en una economía de circulación asimétrica en la que se expresa la obligación moral de los seres humanos hacia los animales. La mencionada asimetría consiste en que los seres humanos hacen con su cuerpo - metabólicamente vinculado con la tierra- un mundo que crea excedentes que son necesarios para la buena vida de los animales. Ellos no pueden dar nada a cambio, pero, más que eso, ya no es necesario el intercambio.

Así el compañero es alguien que con sus tareas vitales y su "preocupación acerca de sí" provee al ser humano - que siempre tiene a la mano y en la lengua a los animales - la oportunidad de alcanzar, en conjunto, un fin común: el bienestar, la satisfacción, y el cuidado de su cuerpo. Este fin común, subraya Korsgaard, no es uno impuesto al animal por parte de los seres humanos, sino que es comunicado por los gestos y los movimientos animales; en ellos 
se expresa la voluntad y agencia en la que el animal dice que aspira a persistir en su vida, pero no en cualquier vida, sino en una que puede quedar exento de ser despojado de su modo particular de hacer mundo. Logro máximo de la capacidad de traducción de una lengua filosófica, a saber: ha descifrado en la "mostración" del animal la compacta solicitud de una comunidad de creaturas que se llaman a sí mismas desde el fondo de la tierra. La filosofía lleva a su fin al animal y a los seres humanos. Adversidades y compañerismos de la filosofía: su gusto animal.

Ese gusto, sin embargo, que va hacia el animal no solo para ofrecer nombres - desde antes de iniciar su camino hacia el animal o lo animal lo aprehendido dentro de un horizonte intelectivo y ético - sino para decidir sobre su vida y su muerte, sobre aquello que, de suyo, le corresponde como viviente terrenal. En este contexto se separan, en sus posibles efectos, las representaciones filosóficas de Wolff y Korsgaard, puesto que, en cada una de ellas, no solo los animales, sino los seres humanos son lanzados hacia futuros distintos: en uno, para persistir en cuanto "hombre" debe repetir espectáculos sangrientos y, en el otro, para ser "creaturas" tienen que crear una comunidad sostenida por una metafísica bondadosa desfondada políticamente. 


\section{Referencias}

Burke, Edmund. A Philosophical Enquiry. Edited by Adam Phillips. Oxford: Oxford University Press, 2008 [1757].

Debord, Guy. La société du spectacle. Troisième édition. Paris: Gallimard, 1992 [1967].

Duque, Félix. Filosofía de la técnica de la naturaleza. Tercera edición. Corregida y aumentada. Madrid: Abada, 2019.

Fuller, B. A. G. "The Messes Animals Make in Metaphysics". Journal of Philosophy 46 (1949): 829-838.

Homero. La Odisea. Translated by José Manuel Pabón. Madrid: Gredos, 1982.

Hosey, Geog, and Melfi, Vicki. Anthrozoology: Human-Animal Interactions in Domesticated and Wild Animals. Oxoford: Oxford University Press, 2019.

Hume, David. An Enquiry Concerning Human Understandig and Other Writings. Cambridge: Cambridge University Press, 2007 [1748].

James, William. The Varieties of Religious Experience. New York: The Library of America, 1987 [1902].

Korsgaard, Christine M. Fellow Creatures. Our Obligations to Other Animals. Oxford: Oxford University Press, 2018.

Kracauer, Siegfried. The Mass Ornament. Weimar Essays. Edited by Thomas Y. Levin. Cambridge and London:: Harvard University Press, 1995 [1963].

Lestel, Dominique. Eat this Book: A Carnivore's Manifesto. Translated by Gary Steiner. New York: Columbia University Press, 2016.

Levinas, Emmanuel. Totalité et infini. Essai sur l' extériorité. Paris: Kluwer Academic, 2010 [1971].

Neira, Hernán. "La díficil distinción entre humanos y animales." Revista de Filosofía 73 (2017): $161-178$.

Pelluchon, Corine. Manifeste animaliste. Paris: Alma Éditeur, 2017.

Phillips, Anne. Our Bodies, Whose Property? Princeton and Oxford : Princeton University Press, 2013.

Ponce León, Juan José. "Estado especista: Proletarización animal y sustracción de la vida. Reflexiones marxistas sobre la cuestión animal.” Revista Latinoamericana de Estudios Críticos Animales II (2018): 199-234.

Rodotà, Stefano. La vida y las reglas: Entre el derecho y el no derecho. Translated by Andrea Greppi. Madrid: Trotta, 2010.

Rodríguez, Federico. Cantos cabríos. Jacques Derrida, un bestiario filosófico. Santiago, Chile: Fondo de Cultura Económica, 2015.

Stanford, Craig B., and Henry T. Bunn. Meat-Eating and Human Evolution. Oxford: Oxford University Press, 2001.

Steward, Helen. A Metaphysics for Freedom. Oxford: Oxford University Press, 2012.

Wolff, Francis. Philosophie de la corrida. Paris: Fayard, 2007. Kindle Edition. 